\title{
Tie your mother down?
}

Received: 6 September 2012

Accepted: 11 September 2012

Published online: 28 September 2012

(C) Springer-Verlag Berlin Heidelberg and ESICM 2012

This editorial refers to the article available at: doi:10.1007/s00134-012-2715-9.

P. E. Spronk (匹)

Department of Intensive Care Medicine,

Gelre Hospitals, Lukas Site, Albert Schweitzerlaan 31,

7334 DZ Apeldoorn, The Netherlands

e-mail: p.spronk@gelre.nl

Tel.: +31-55-5818450

P. E. Spronk

Department of Intensive Care Medicine,

Academic Medical Center, University of Amsterdam,

Amsterdam, The Netherlands

P. E. Spronk

HERMES Critical Care Group,

Amsterdam, The Netherlands

The album "A Day at the Races" contains a song written by Brian May in 1976 entitled "Tie Your Mother Down" which contains the words "Tie your mother down, or you ain't no friend of mine." This quote seems apt when the image of an agitated and delirious ventilated patient in the intensive care unit (ICU) comes to mind. In this issue of Intensive Care Medicine, de Jonghe et al. [1] describe the results of a survey addressing the perceived utilization of physical restraints (PR) in mechanically ventilated patients in France. The aim of their survey was to identify clinical and structural factors influencing the use of PR in this specific group of patients in the ICU. The authors are to be congratulated with their effort to investigate this important issue in daily critical care. Why are so many patients tied down, even though they seem to be perfectly at rest, or are even deeply comatose or even paralysed? These authors show that $29 \%$ of the participating ICUs would appear to tie down $50 \%$ of ICU patients despite these patients being in an awake, calm, and cooperative state; $81 \%$ of participating centers would appear to adapt the tightness of the PR to the patient's condition. Almost $80 \%$ of participating ICUs stated that they do not believe that the use of PR in mechanically ventilated patients could be discontinued. Moreover, in only $56 \%$ of the ICUs was the reason for using PR explained to the relatives, possibly leading to conflicts and disputes with the ICU team. This state of affairs seems hardly acceptable in an era where patients and their relatives play an increasingly important role in the recovery process from critical illness. However, in the centers surveyed, the median patient-to-nurse ratio was $2.8\left(P_{25}-P_{75}=2.5-3.0\right)$, which may well explain the PR policy in French ICUs. In other countries, this ratio may be 1.0 depending on local guidelines. Indeed, in a point prevalence study in 34 adult ICUs in nine European countries, the patient-to-nurse ratio, being on a ventilator, and the size of the ICU were all strongly related to PR use [2].

Although virtually every ventilated patient was placed in a deep coma not so many years ago, more recent studies have shown that less sedation and the involvement of the patient in their recovery phase result in better outcomes [3, 4]. Even in neurointensive care patients, increasing mobility has been found to result not only in a reduced length of stay in the ICU, but also in a reduction in the number of infections [5]. These beneficial effects are due not only to less sedation being used in most ICUs in the Western world in accordance with protocols addressing the level of sedation, but also to the use of short-acting sedatives, such as dexmedetomidine [6]. In addition, delirium, with its associated inherent problems of cognitive dysfunction in patients who suffer from that condition, has been recognized as an important factor in 
determining final outcome [7]. Although a general consensus on the best pharmacological treatment of delirium is far from being reached, there is compelling research supporting the important role of non-pharmacological measures in patients with delirium [8], which should probably also include the discontinuation of PR use. However, this aspect has not been systematically investigated. Current studies are even incorporating cognitive stimulation in the treatment of critically ill patients [9]. There is some evidence that the use of PR is a risk factor for agitation, delirium, and even self-extubation. A recent study demonstrated that, among other risk factors, the use of $\mathrm{PR}$ is associated with a significantly higher incidence of self-extubation (odds ratio $>3$ ) [10]. Although one may argue that this is probably the result of an epiphenomenon due to confounding, i.e., agitated patients have a higher propensity for self-extubation as well as being put in PR, the authors' findings suggest an independent association between the use of PR and self-extubation.

Importantly, surveys of clinicians' perceptions of their clinical practice are often not accurate predictors of actual practice. In the study by de Jonghe et al. one intensivist per unit was asked to complete the questionnaire and provide data on overall approach to the use of PR by all
ICU physicians and nurses in their unit. Therefore, we cannot assume that these data accurately measure actual care delivered. However, this limitation to the survey should not divert us from the conclusions that can be reached based on the reported use of PR. In addition, in view of the reported differences in PR use among French ICUs, this study raises the question of whether differences in local culture and experience play a role in the decision of how and when to apply PR. A study involving psychiatric patients demonstrated that the team climate, perception of staff regarding aggression, as well as organizational factors are all associated with the use of restraint [11]. This result underlines the importance of the message which can be derived from the survey of de Jonghe et al. Healthcare providers should carefully think about using PR in mechanically ventilated patients, develop a local protocol, explain the use of PR to both patients and relatives, and reassess the use of PR at least on a daily basis, with the preference going adapting the level of sedation and monitoring the mental state of the patient.

Conflicts of interest None.

\section{References}

1. de Jonghe B, Constantin J, Chanques G, Capdevilla X, Lefranc J, Outin H, Mantz J (2012) Physical restraint in mechanically ventilated ICU patients: a French practice survey. Intensive Care Med. doi:10.1007/s00134-012-2715-9

2. Benbenbishty J, Adam S, Endacott R (2010) Physical restraint use in intensive care units across Europe: the PRICE study. Intensive Crit Care Nurs 26:241-245

3. Girard TD, Kress JP, Fuchs BD, Thomason JW, Schweickert WD, Pun BT, Taichman DB, Dunn JG, Pohlman AS, Kinniry PA, Jackson JC, Canonico AE, Light RW, Shintani AK, Thompson JL, Gordon SM, Hall JB, Dittus RS, Bernard GR, Ely EW (2008) Efficacy and safety of a paired sedation and ventilator weaning protocol for mechanically ventilated patients in intensive care (awakening and breathing controlled trial): a randomised controlled trial. Lancet 371:126-134

4. Schweickert WD, Kress JP (2011) Implementing early mobilization interventions in mechanically ventilated patients in the ICU. Chest

140:1612-1617
5. Titsworth WL, Hester J, Correia T, Reed R, Guin P, Archibald L, Layon AJ, Mocco J (2012) The effect of increased mobility on morbidity in the neurointensive care unit. J Neurosurg 116:1379-1388

6. Jakob SM, Ruokonen E, Grounds RM, Sarapohja T, Garratt C, Pocock SJ, Bratty JR, Takala J, Dexmedetomidine for long-term sedation I (2012) Dexmedetomidine vs midazolam or propofol for sedation during prolonged mechanical ventilation: two randomized controlled trials. JAMA 307:1151-1160

7. Ely EW, Shintani A, Truman B, Speroff T, Gordon SM, Harrell FE Jr, Inouye SK, Bernard GR, Dittus RS (2004) Delirium as a predictor of mortality in mechanically ventilated patients in the intensive care unit. JAMA 291:1753-1762

8. Hipp DM, Ely EW (2012)

Pharmacological and nonpharmacological management of delirium in critically ill patients. Neurotherapeutics 9:158-175
9. Brummel NE, Jackson JC, Girard TD, Pandharipande PP, Schiro E, Work B, Pun BT, Boehm L, Gill TM, Ely EW (2012) A combined early cognitive and physical rehabilitation program for people who are critically ill: the activity and cognitive therapy in the intensive care unit (ACT-ICU) trial. Phys Ther

10. da Silva PS, Fonseca MC (2012) Unplanned endotracheal extubations in the intensive care unit: systematic review, critical appraisal, and evidencebased recommendations. Anesth Analg 114:1003-1014

11. De Benedictis L, Dumais A, Sieu N, Mailhot MP, Letourneau G, Tran MA, Stikarovska I, Bilodeau M, Brunelle S, Cote G, Lesage AD (2011) Staff perceptions and organizational factors as predictors of seclusion and restraint on psychiatric wards. Psychiatr Serv $62: 484-491$ 